\title{
Expression of major histocompatibility antigens in human chronic pancreatitis
}

\author{
R P Jalleh, J A Gilbertson, R C N Williamson, S D Slater, C S Foster
}

\begin{abstract}
T-lymphocytic infiltration of the exocrine pancreas and liver in patients with chronic pancreatitis has suggested that cell mediated immune mechanisms may play a part in the pathogenesis of this disease. As expression of major histocompatibility (MHC) antigens is a prerequisite for organ specific autoimmunity, the expression of HLA class I ( $\beta 2$-microglobulin) and class II (HLA-DR) determinants have been analysed, together with the presence of $T$-lymphocytes, in 93 patients ( 64 men and 29 women, mean age 40.6 years) having an operation for chronic pancreatitis. Ethanol (63 patients), recurrent acute pancreatitis (12), congenital lesions (2), and unknown (16) were suggested to be the causes of the disease. Immunohistochemical staining of formalin fixed and paraffin wax embedded tissue sections used conventional immunohistochemical techniques with specific anti-serum samples. No MHC expression was identified in 10 histologically normal pancreatic control specimens or in four cases of chronic pancreatitis secondary to obstruction by neuroendocrine tumours within the head of the pancreas. $\beta 2$-microglobulin expression by pancreatic exocrine epithelial cells was seen in 76 chronic pancreatitis specimens (82\%) while HLA-DR was present in $61(66 \%)$. Simultaneous expression of both class I and II determinants was seen in $53(57 \%)$ of cases. MHC determinant expression was not found in 10 cases $(11 \%)$ of chronic pancreatitis. In the positive specimens, expression was confined to ductal and ductular (interlobular and intralobular) epithelium with no staining of acinar cells. Staining was not related to the suspected cause of the disease or age. T-lymphocytes were more prominent in chronic pancreatitis mean (SEM) (131 (15) cells per high powered field) than controls (5 (1), p<0.01). Aberrant MHC expression by exocrine pancreatic ephithelial cells occurring in the presence of an appreciable $T$-cell infiltration confirmed that the appropriate cellular conditions were present for cell mediated cytotoxicity to contribute to the pathogenesis of chronic pancreatitis.
\end{abstract}

(Gut 1993; 34: 1452-1457)

Chronic pancreatitis is a progressive inflammatory disease characterised by intractable pain, irreversible morphological change, and loss of pancreatic exocrine and endocrine function. The radical operations that may be required to control pain often exacerbate both exocrine and endocrine loss. While alcohol is the most frequently implicated cause, non-alcohol associated (idiopathic) cases account for between nine and 41 per cent of all chronic pancreatitis, the precise incidence depending upon the population studied. ${ }^{2}$ Rarer causes include hypercalcaemia, hyperlipidemia, hereditary factors and, in tropical countries, protein and fat malnutrition. ${ }^{3}$ In individual patients, however, the precise cause and pathogenesis often remain unknown. In this report, we explore the possible role of autoimmune mechanisms in the cause and pathogenesis of chronic pancreatitis.

In alcoholic chronic pancreatitis, changes in pancreatic juice may lead to precipitates of protein and calcium, which obstruct the ducts, causing ulceration, fibrosis, and subsequent atrophy of exocrine pancreatic epithelium distal to the obstruction. ${ }^{56}$ This hypothesis has evolved after the examination of 'end stage' chronic pancreatitis in which calcium deposition is common, ${ }^{78}$ but does not identify the events that start the damage nor does it explain the development of the disease in non-alcoholics. Moreover, many non-alcoholics do not develop chronic pancreatitis. Chronic pancreatitis clearly comprises more than one cause, and Sarles has emphasised the morphological distinction between the chronic calcifying form and 'primary inflammatory pancreatitis." Klöppel and Maillet discovered protein plugs and calcification only infrequently in early chronic pancreatitis, suggesting that these are unlikely to be causal factors but rather epiphenomena occurring during progression of the disease. ${ }^{10}$

Previous studies of liver biopsy specimens in patients with severe chronic pancreatitis suggest that immunological mechanisms could play a part in its pathogenesis. ${ }^{112}$ Even when alcohol was the suspected cause, hepatic parenchymal damage was minimal compared with the severity of pancreatic disease, showing that alcohol may not be the sole injurious factor. T-lymphocyte infiltration in the absence of hepatocyte damage would be consistent with the transit of inflammatory cells originating within the inflamed pancreas. Autoantibodies reactive with pancreatic acinar cells and ductal antigens have been described in patients with chronic pancreatitis, ${ }^{1314}$ as have activated lymphocytes specifically sensitised to crude pancreatic antigens, ${ }^{15}$ supporting the participation of autoimmune mechanisms in some types of chronic pancreatitis. ${ }^{16} 17$

During the development of organ specific autoimmunity, initial events entail aberrant expression of major histocompatibility complex (MHC) molecules by cells that do not express such determinants. ${ }^{18}$ Class I antigens are expressed by most nucleated somatic cells but not by exocrine pancreatic cells. ${ }^{19}$ Normal acinar and ductal pancreatic epithelial cells do not express MHC class II determinants either, ${ }^{20}$ but 
some expression has been reported in two small series of patients with chronic or 'obstructive' pancreatitis. ${ }^{2122}$ Possible autoimmune recognition of pancreatic epithelial cells occurring early in some types of chronic pancreatitis does not exclude alcohol from being an important cause or oppose the hypothesis that proteinaceous and calcific deposits contribute to the general pathogenesis of the disease. Confirmation of autoimmune mechanisms, however, might help define a population of patients who could benefit from non-surgical management of chronic pancreatitis.

\section{Patients and methods}

\section{PATIENTS}

Pancreatic specimens were reviewed from a personal series (RCNW) of 102 patients having an operation for chronic pancreatitis from 1977 to 1990 at Bristol Royal Infirmary or the Hammersmith Hospital, London. Of these, biopsy samples from nine patients were considered either not to contain sufficient material to permit an accurate histological diagnosis or sufficient epithelial elements to assess immunostaining adequately. These sections were excluded from this study. The 93 patients now reported comprised 64 men and 29 women with a mean age of 40.6 years (range $20-72$ years). The main cause of the disease was ethanol $(63$ patients). Causes in the other 28 patients included previous acute pancreatitis in 12 , choledochal cyst in one and pancreas divisum in another. No cause was identified in the remaining 16 patients.

\section{CHRONIC PANCREATITIS SPECIMENS}

Wherever possible, pancreatic resection specimens were received fresh and dissected in a standard manner before fixation. Blocks of tissue for examination were taken transversely across

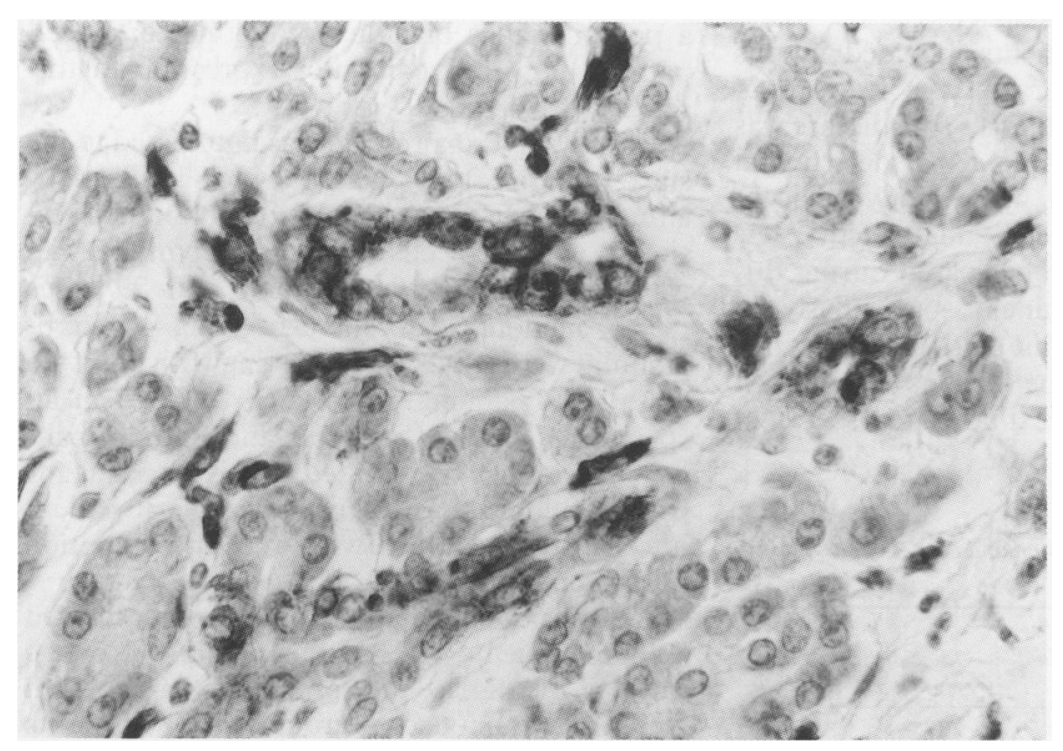

Figure 1: Section of human pancreas from a region containing early morphological changes of chronic pancreatitis. Intralobular ductules selectively express $M H C$ class I determinants. $(\beta 2$-microglobulin). Original magnification $\times 750$. the pancreas through cellular regions intermediate between the resection margins and the macroscopically most fibrous and scarred parts of the specimens. These blocks were then bisected vertically to allow examination of the parenchyma both in the regions surrounding the central ducts and at the periphery of the tissue. Blocks taken from densely fibrotic or heavily calcified regions of the specimens were avoided.

CONTROL PANCREATIC SPECIMENS

Ten morphologically normal pancreatic specimens and four specimens of chronic pancreatitis secondary to obstruction by neuroendocrine tumours within the head of the pancreas were used as control tissues. The normal tissues were obtained from patients undergoing distal pancreatic resections for small non-obstructing pancreatic neuroendocrine tumours, patients with suspected chronic pancreatitis but normal pancreatic histology, or where the distal pancreas was excised whole in a radical cancer operation. The tissue blocks were taken transversely across the pancreatic specimens through the regions immediately adjacent to, but at $0.5 \mathrm{~cm}$ from, resection margins.

\section{IMMUNOHISTOCHEMISTRY}

Class I MHC expression was determined by identification of $\beta_{2}$-microglobulin, the non-polymorphic light chain component of human class I antigens, using polyclonal rabbit antibody (Dako Ltd, High Wycombe, UK) diluted to $1: 1000$ in $120 \mathrm{mmol} / \mathrm{l}$ sodium phosphate buffered saline (PBS, pH 7•4). Monoclonal mouse anti-human HLA-DR (Dako Ltd), which reacts with the $\beta$-chain of all products of the HLA gene subregions DP, DQ, and DR, was diluted to 1:150 in PBS to identify class II MHC expression. Monoclonal antibody UCHL1 (antihuman $\mathrm{T}$ cell) was obtained as a gift from $\mathrm{Dr}$ Peter Beverley, University College Hospital, London and used at a 1:10 dilution. Human tonsillar tissue was used as the positive control for the three antibodies used.

Formalin fixed and paraffin wax embedded tissue sections ( $2 \mu \mathrm{m}$ thickness) were dewaxed in TCF 30 (Infrakem Ltd, Wigan, UK), brought to water through graded ethanols and digested with trypsin $\left(0.1 \% \mathrm{wt} / \mathrm{vol}\right.$ in aqueous $0.1 \% \mathrm{CaCl}_{2}$ for five minutes at $37^{\circ} \mathrm{C}$ ). Endogenous peroxidase was blocked with $0.3 \%$ hydrogen peroxide $\left(\mathrm{H}_{2} \mathrm{O}_{2}\right.$ in distilled water for 30 minutes at room temperature). A peroxidase anti-peroxidase technique was used to detect bound $\beta_{2}$-microglobulin. HLA-DR staining was performed by the avidin-biotin-peroxidase complex method using the Vectastain ABC kit (Vector Laboratories, Burlingame, USA) ${ }^{23}$ A conventional indirect immunoperoxidase technique was used for detection of bound HCHL1. In all cases, sections were incubated with primary antibodies overnight at $4^{\circ} \mathrm{C}$. The resultant immune peroxidase complexes were developed in $0.5 \%$ (vol/vol) 3,3'-diaminobenzidine hydrochloride (DAB, Aldrich, Gillingham, Dorset, UK) in PBS containing $0.03 \%$ (vol/vol) $\mathrm{H}_{2} \mathrm{O}_{2}$. Sections were counterstained with haematoxylin and 


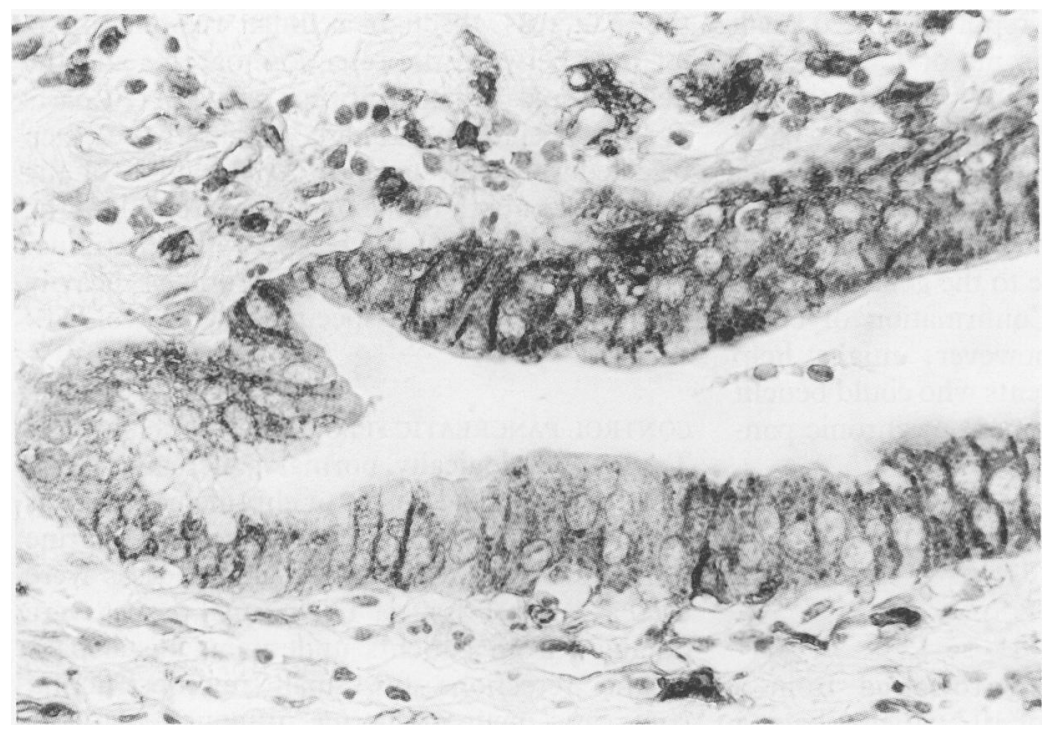

Figure 2: Section of human pancreas containing an interlobular duct with adjacent chronic inflammatory infiltrate. There is focal and selective expression of class II MCH determinants $(H L A-D R)$ by ductal epithelial cells and adjacent lymphocytes. Original magnification $\times 600$. mounted in Pertex (Histolab, Hemel Hempstead, UK). Expression of $\beta_{2}$-microglobulin and HLA-DR were assessed as either being positive or negative in the epithelial elements (acinar, ductular, or ductal), mononuclear cells, and islets. Lymphocyte morphometry was performed using a $10 \times 10 \mathrm{~mm}$ graticule within the microscope ocular at $\times 400$ magnification. For each specimen, the number of T-lymphocytes per high power field (hpf) in three areas of maximal infiltration was counted and a mean value calculated.

\section{STATISTICS}

Statistical analyses were performed using $\chi^{2}$ and unpaired Student's $t$ tests.

\section{Results}

HISTOPATHOLOGICAL ASSESSMENT

Tissues from the 93 patients included in this study contained the characteristic features of chronic pancreatitis. In all cases, the disease was focal in distribution. Lobulo-acinar destruction was severe in some foci while many adjacent lobules were morphologically unaffected. Islets of Langerhans seemed to be spared during this process and were prominent, particularly in those regions where exocrine epithelial structures had been destroyed. Tissue sections were chosen to show the early rather than later stages of

TABLE I Comparison of major histocompatibility antigen expression and causes of chronic pancreatitis $(n=93)$

\begin{tabular}{llllll}
\hline & $\begin{array}{l}\text { Ethanol } \\
\text { No\% }\end{array}$ & $\begin{array}{l}\text { Previous acute } \\
\text { pancreatitis } \\
\text { No\% }\end{array}$ & $\begin{array}{l}\text { Congenital } \\
\text { No\% }\end{array}$ & $\begin{array}{l}\text { Idiopathic } \\
\text { No\% }\end{array}$ & Total \\
\hline No of patients & 63 & 12 & 2 & 16 & 93 \\
B2-microglobulin positive & $50(79)^{\star}$ & $10(83)^{\star}$ & $1(50)^{\star}$ & $15(94)^{\star \star}$ & $\begin{array}{l}76(82) \\
\text { HLA-DR positive }\end{array}$ \\
\hline $29(61)^{\star}$ & $6(50)^{\star}$ & $2(100) \dagger$ & $14(88) \ddagger$ & $61(66)$ \\
\hline
\end{tabular}

Statistical analysis; ${ }^{\star} \mathrm{p}>0.5 v$ total, ${ }^{\star \star} \mathrm{p}>0.1 v$ total, fno analysis, $\neq 0.10>\mathrm{p}>0.05 v$ total.
TABLE II MHC expression according to age group

\begin{tabular}{llll}
\hline $\begin{array}{l}\text { Age group } \\
(y)\end{array}$ & No & \begin{tabular}{l}
$\begin{array}{l}\beta 2 m \\
\text { positive }\end{array}$ \\
\hline$<40$
\end{tabular} & $\begin{array}{l}\text { HLA-DR } \\
\text { positive }\end{array}$ \\
\hline $40-55$ & 39 & 31 & 25 \\
$>55$ & 44 & 37 & 29 \\
Total & 10 & 8 & 7 \\
\hline
\end{tabular}

${ }^{\star} \mathrm{p}>0.5 v$ no in each age group of population studied.

chronic pancreatitis. In these, neither protein plugging of major ducts nor calcification of minute ducts were identified in the specimens included in this study. Sections of endstage chronic pancreatitis comprising only a few residual epithelial elements together with nerves and vascular structures in dense fibrous connective tissue, together with focal calcification, were avoided in the assessment of MHC expression.

CONTROL IMMUNOHISTOCHEMICAL STUDIES

No class I or class II MHC expression by exocrine epithelial cells of any of the 10 normal control specimens, or by the four cases of obstructive chronic pancreatitis, was identified. Only a few scattered foci of T-lymphocytes were seen in the interlobular stroma of these specimens.

CLASS I MHC ( $\beta 2$-MICROGLOBULIN) EXPRESSION Of the 93 cases of chronic pancreatitis studied, class I MHC expression was seen in the epithelial elements of $76(82 \%)$ specimens. Expression was focal and varied. Positive staining was confined to intralobular and interlobular ductules (Fig 1) and interlobular ducts; there was no staining identified in acinar cells. In 27 biopsies; this expression affected both ductular and ductal epithelium, while in another 44 cases $\beta_{2}$-microglobulin staining was limited to either ductules (28 specimens) or ducts (16 specimens). This pattern of distribution was not assessed in the remaining five biopsies because of the absence of either of these structures. We could not identify a predominance of either a ductular or ductal pattern of $\beta_{2}$-microglobulin expression in this series $\left(\chi^{2}=3 \cdot 01,0 \cdot 10>p>0 \cdot 05\right)$.

Class I MHC expression was not related to the sites of maximal lymphocytic infiltration, although concurrent $\beta_{2}$-microglobulin expression by epithelial cells and adjacent lymphocytes was identified in 10 specimens. In 79 cases $(85 \%)$, mononuclear cells expressing $\beta_{2}$-microglobulin were present, contrasting with only two cases $(20 \%)$ among controls $(p<0.001)$. In all specimens, both of controls and chronic pancreatitis, islet cells exhibited positive staining for $\beta_{2}$-microglobulin. This provided a convenient internal positive control within each tissue section for this antibody.

Analysis of the data for alcohol intake showed 50 of 63 patients $(79 \%)$ with a possible alcoholic cause of the disease to express $\beta_{2}$-microglobulin while in the non-alcohol group, 26 of 30 patients with chronic pancreatitis (87\%) expressed this determinant. The differences between the groups were not significant $(p>0 \cdot 5)$. 
CLASS II MHC (HLA-DR) EXPRESSION

HLA-DR expression was identified in $61(66 \%)$ specimens. This followed a similar pattern of distribution to $\beta_{2}$-microglobulin. No expression was seen in any acinar cell, positive staining being confined to ductular and ductal epithelium. In 40 cases, HLA-DR was identified in both these structures while expression was restricted to ductules in 12 cases and to ducts in seven cases. Absence of either structure precluded analysis of distribution in the remaining two cases. There was also no relation between areas of HLA-DR expression and foci of lymphocyte infiltration. Concurrent staining of both epithelial elements and adjacent lymphocytes was seen in eight biopsy specimens (Fig 2). Mononuclear cells expressed HLA-DR in 88 $(95 \%)$ cases compared with five $(50 \%)$ in controls $(\mathrm{p}<0.001)$. In five cases, a population of
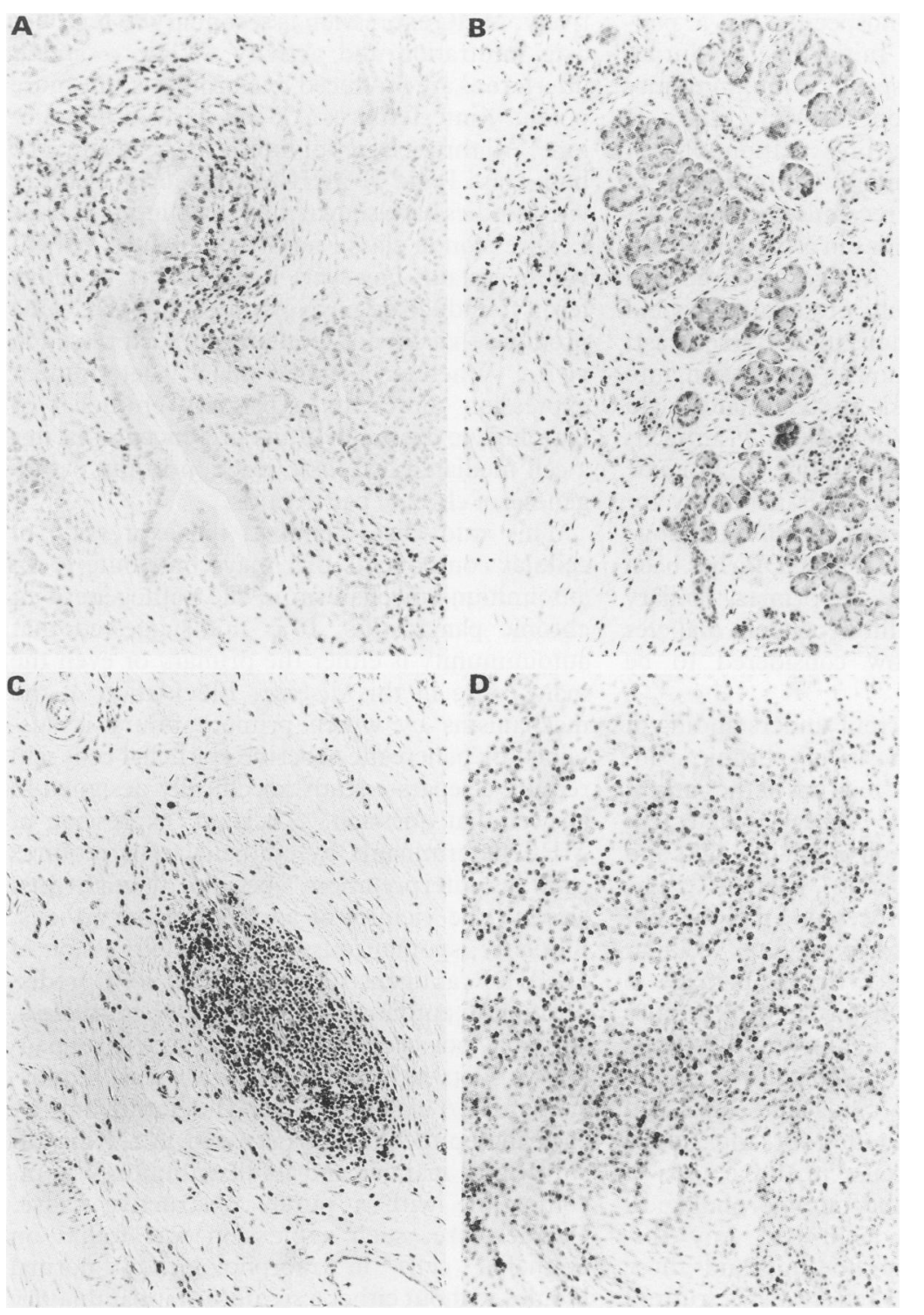

Figure 3: Different patterns of T-lymphocyte distribution identified in chronic pancreatitis by immunostaining with UCHL1. Original magnification $\times 125$. (A) focal periductal infiltration. The adjacent acinar structures do not contain an inflammatory infiltrate; $(B)$ perilobular infiltrate. T-cells are loosely scattered around individual

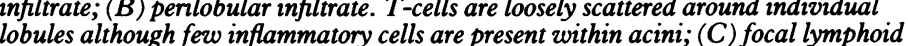
aggregate. These structures are identified, not infrequently, in late stage chronic pancreatitis; $(D)$ diffuse inflammation. Sheets of mixed chronic inflammatory cells effacing the underlying pancreatic architecture. islet epithelial cells and adjacent intra-islet endothelial cells were HLA-DR positive. In these tissues, however, not all the islets contained positive cells.

Analysis of the data for alcohol intake showed 29 of 63 patients $(61 \%)$ with a possible alcoholic cause of the disease to express class II MHC determinants while in the non-alcohol group, 22 of 30 patients with chronic pancreatitis $(73 \%)$ expressed this determinant. The differences were marginally significant $(0.05>p>0.02)$.

\section{COMBINATION OF CLASS I AND II DETERMINANTS}

Simultaneous expression of both class I and II MHC determinants was seen in $53(57 \%)$ cases. Twenty two specimens showed only $\beta_{2}$-microglobulin staining while eight cases were only HLA-DR positive. There was no relation between either $\beta_{2}$-microglobulin or HLA-DR expression and the underlying cause (Table I). MHC expression was also not age related (Table II).

\section{CHARACTERISATION OF T-LYMPHOCYTES}

T-lymphocytes were identified in all tissue sections studied. These cells were more prominent in chronic pancreatitis specimens, however, with an estimated density mean (SEM) of 131 (15) cells per hpf compared with controls (5 (1), p<0.01). The density of lymphocyte infiltration varied among specimens. A wide variety of morphological patterns of T-lymphocyte distribution was identified (Fig 3). The proportion of T-lymphocytes to total mononuclear cells per hpf ranged from $19 \%$ to $78 \%$. No direct correlation was seen between T-lymphocyte densities in 38 pancreatic specimens and the periportal regions of corresponding liver biopsy specimens taken at the same operation. ${ }^{11}$

\section{Discussion}

Abnormal expression of class I or class II MHC determinants, or both by exocrine epithelial cells has been found in $89 \%$ of cases of chronic pancreatitis. In addition, all cases of chronic pancreatitis contained significantly increased numbers of $\mathrm{T}$-lymphocytes compared with controls. Although no $\beta_{2}$-microglobulin expression was identified in control exocrine tissues despite positive staining of islet cells, $63 \%$ of chronic pancreatitis specimens showed positive interlobular and intralobular ductular staining, not previously described. ${ }^{19} 20$ Class I determinants are present on all nucleated cells, ${ }^{24}$ their expression is variable, ${ }^{25}$ but a detailed analysis of these determinants failed to detect class I HLA-ABC heavy chain antigens in the exocrine pancreas. ${ }^{19}$ Thus, expression of $\beta_{2}$-microglobulin in chronic pancreatitis was abnormal and sufficiently enhanced to suggest a state of hyperexpression analogous to that proposed for type I insulin dependent diabetes mellitus. ${ }^{26}$

In agreement with earlier reports, ${ }^{19-21}$ this study found that normal pancreatic epithelial cells did not express HLA-DR antigens, yet such expression was seen in two thirds of the chronic pancreatitis specimens. There was simultaneous 
expression of class I and II antigens in 53 specimens $(57 \%)$, while HLA-DR expression alone was rare $(9 \%)$. We also found a substantial increase in MHC expression by mononuclear cells in chronic pancreatitis specimens and such expression by T-lymphocytes is necessary for the antigen recognition process. ${ }^{27}$ Confirmation that these modules are expressed at readily detectable values by pancreatic exocrine ductular epithelial cells, in association with a considerable T-lymphocyte infiltration, establishes the presence of known cellular components required for the start of an autoimmune reaction in a large proportion of patients with chronic pancreatitis.

Participation of immune mechanisms in the cause and pathogenesis of chronic pancreatitis has been suspected as increased serum concentrations of immunoglobulins (IgA, $\operatorname{IgM})$ and changes in concentrations of circulating T-lymphocytes were reported in $1974 . .^{28}$ Later, Nerenberg et al detected raised values of a circulating antibody monospecific for a pancreatic acinar antigen. ${ }^{29}$ Initial events during development of organ specific autoimmunity entail aberrant expression of MHC class II antigens, ${ }^{18}$ thus allowing presentation of cell specific antigens to potentially autoreactive $T$ lymphocytes. These cells recognise protein fragments and synthetic peptides in association with class I and II molecules. Antigens synthesised endogenously by target cells preferentially yield complexes with class I molecules. By contrast, antigens acquired exogenously and taken into target cells by endocytosis preferentially yield class II complexes. ${ }^{30}$ While class I antigens participate in antigenic presentation to cytotoxic T-lymphocytes, class II MHC is necessary for similar presentation to helper T-cells. De novo expression of class II MHC (HLA-DR) has been shown in diseases such as primary biliary cirrhosis $^{31}$ and type I insulin dependent diabetes mellitus, ${ }^{26}$ conditions now considered to be immune mediated.

Our data add to the current understanding of the cause and pathogenesis of chronic pancreatitis. Sarles et al suggested that in the earliest stages, before any cellular damage is detected, there is luminal precipitation of calcium salts and a special pancreatic stone protein. ${ }^{3}$ The molecular basis for this process is unknown but could include direct ethanolic toxicity, ${ }^{32}$ cellular adaptation to ethanol, ${ }^{3}$ or cytotoxic damage to the cell membrane. ${ }^{33}$ Each mechanism implies change at a cellular level before the lithogenic process. In a recent histopathological and immunohistochemical study, Suda et al concluded that protein plug obstruction of the ductal system is not the main cause in the genesis of ethanolic pancreatitis, ${ }^{34}$ and our morphological findings support this conclusion. Any discrepancies between these findings and those previously reported could reflect a spectrum of different causal factors or studies conducted at different stages in disease progression. In our series, absence of calcification from tissues containing early changes of chronic pancreatitis agrees with the recent findings of Klöppel and Maillet. ${ }^{10}$

We have not yet defined the characteristics of those patients who showed abnormal pancreatic expression of MHC antigens, nor have we yet ascertained whether expression is restricted to a specific subpopulation of patients. There was no relation between abnormal $\mathrm{MCH}$ expression and either age or the currently accepted causes of the disease, and our findings do not support a clear differentiation between ethanolic and nonethanolic pancreatitis. ${ }^{35}$ Indeed, the classification of chronic pancreatitis based on the causes and morphological patterns may have to be reviewed in the light of the present and further immunological studies. Our findings suggest that a cell mediated immune reaction represents one stage in a 'multistep' pathogenetic process and could act as a common pathway in different types of chronic pancreatitis. In some cases of chronic pancreatitis, different causes might induce abnormal MHC expression and allow an autoimmune reaction to develop. This process seems to begin in the ductal epithelium and the interlobular and intralobular ductules. Alternatively, MHC expression is secondary to lymphocyte infiltration and activity. While $\alpha$ and $\beta$ interferons are produced by fibroblasts, the more potent $\gamma$ interferon is a T-cell derived lymphokine. All three classes of interferons can enhance both class I and II MHC expression, ${ }^{36}{ }^{37}$ and in vitro studies have shown interferon induced class I expression in class I negative cell lines. ${ }^{38}$ What is less certain, however, is the ability of interferon to induce de novo synthesis of MHC gene products that are not spontaneously expressed in vivo. ${ }^{21}$ Whether aberrant $\mathrm{MHC}$ determinant expression represents a primary epithelial or lymphocyte dysfunction, its presence implicates a cell mediated cytotoxic reaction in the pathogenesis of chronic pancreatitis.

This study has identified the expression of cellular components that may contribute to an autoimmune mechanism in the pathogenesis of chronic pancreatitis. It is not suggested that autoimmunity is either the primary or even the main cause in this disease. Elucidation of the mechanisms by which primary injury is sustained by pancreatic exocrine epithelial cells will require a separate study specifically designed to answer that question. 'Aberrant' expression of MHC determinants by epithelial cells requires cautious interpretation, ${ }^{39}$ because it might just arise in the vicinity of an inflammatory focus. Similarly, spontaneous ('normal') expression of HLA-DR antigens does not point to a predisposition to autoimmune disease..$^{40}$ Nevertheless, we have not seen calcific obstruction of pancreatic ducts early in the disease process. Expression of HLA class I and class II determinants by exocrine epithelial cells occurred in a regional, sublobular manner and its distribution was incompatible with a purely obstructive cause. Furthermore, such expression was found on epithelial cells in morphologically normal lobules without either a significant inflammatory component or evidence of epithelial destruction. Additional studies are now required to elucidate the nature and timing of this cell mediated immune reaction. If subsequently proved, it holds exciting treatment prospects for changing the clinical management of this difficult disease. 
We are grateful for the assistance of Professor J W B Bradfield, Department of Histopathology, University of Bristol, in permitting unreserved access to the archived specimens at the Bristol Royal Infirmary. Dr S D Slater acknowledges support of the British Digestive Foundation during these studies.

1 Sarner M, Cotton PB. Classification of chronic pancreatitis Gut 1984; 25: 756-9.

2 Singh SM, Reber HA. The pathology of chronic pancreatitis. World F Surgery 1990; 14: 2-10.

3 Sarles H, Bernard JP, Gullo L. Pathogenesis of chronic pancreatitis. Gut 1990; 31: 629-32.

4 Klöppel G, Maillet B. Pseudocysts in chronic pancreatitis: A morphological analysis of 57 resection specimens and 9 autopsy pancreata Pancreas $1991 \cdot 3 \cdot 266-74$.

5 Guy O, Robles-Diaz G, Aldrich Z, Sahel J, Sarles H. Protein content of precipitates present in pancreatic juice of alcoholic subjects and patients with chronic calcifying pancreatitis. Gastroenterology 1983; 84: 102-7.

6 Sarles H, Sarles JC, Camatte R, Muratore R, Gaini M, Guien C, et al. Observations on 205 confirmed cases of acute pancreatitis, recurring pancreatitis and chronic pancreatitis. Gut 1965; 6: 545-59.

7 Payan H, Sarles H, Demirdjian M, Gauthier AP, Cros RC, Durbec JP. Study of the histological features of chronic pancreaqtitis by correspondence analysis. Identification of chronic calcifying pancreatitis as an entity. Biomedicine 1972; 18: 663-70.

8 Uys CJ, Bank S, Marks IN. The pathology of chronic pancreatitis in Cape Town. Digestion 1973; 9:454-68.

9 Sarles H. Chronic calcifying pancreatitis - chronic alcoholic pancreatitis. Gastroenterology 1974; 66: 604-16

10 Klöppel G, Maillet B. Chronic pancreatitis: Evolution of the disease. HepatoGastroenterology 1991; 38: 408-12.

11 Jalleh RP, Gilbertson JA, Williamson RCN, Foster CS. A morphological and immunohistochemical analysis of the human liver in chronic pancreatitis. Gut 1991; 32: 1386-91.

12 Haboubi NY, Ali HH, Braganza JM. Altered liver histology in patients with pancreatitis: A clue to etiology? Mt Sinaif Med 1986; 53: 380-8.

13 Rumessen JJ, Marner B, Thorsgaard Pedersen N, Permin H. Autoantibodies in chronic pancreatitis. Scand $\mathcal{F}$ Gastroenterol Autoantibodies in

14 Thal AP, Murray MJ, Egner W. Isoantibody formation in chronic pancreatic disease. Lancet 1959; i: 1128-9.

15 Schütt C, Friemel H, Schulze HA, Zubaidi G. Specific lymphocyte sensitization in chronic pancreatitis. Digestion 1975; 13: 308-11.

16 Lankish PG, Koop H, Seelig R, Seelig HP. Antinuclear and pancreatic acinar cell antibodies in pancreatic diseases. Digestion 1981; 21 : 65-8.

17 Lendrum $R$, Walker G. Serum antibodies in human pancreatic disease. Gut 1975; 16: 365-71.

18 Bottazzo GF, Pujal-Borell R, Hanafusa T, Feldman M. Role of aberrant HLA-DR expression and antigen presentation in induction of endocrine autoimmunity. Lancet 1983; ii: induction

19 Daar AS, Fuggle SV, Fabre JW, Ting A, Morris PJ. The detailed distribution of HLA-A,B,C antigens in normal
human organs. Transplantation $1984 ; 38: 287-92$.

20 Lautenschlager I, Inkinen K, Taskinen E, Charles MA, Hayry $\mathrm{P}$, Major histocompatibility complex protein expression on pancreas and pancreatic islet endocrine cell subsets. Am F Pathol 1989; 135: 1129-37.
21 Bedossa P, Bacci J, Lemaigre G, Martin E. Lymphocyte subsets and HLA-DR expression in normal pancreas and chronic pancreatitis. Pancreas 1990; 5: 415-20.

22 Bovo P, Mirakian R, Merigo F, Angelini G, Cavallini G, Rizzini $\mathrm{P}$, et al. HLA molecule expression on chronic pancreatitis specimens: Is there a role for autoimmunity? A preliminary study. Pancreas 1987; 3: 350-6.

23 Hsu $M$, Raine L, Fanger $H$. The use of avidin-biotin peroxydase complex (ABC) in immunoperoxydase techniques: comparison between $\mathrm{ABC}$ and unlabelled antibody niques: comparison between ABC and unlabelled antibody

24 Bell JI, Todd JA, McDevitt HO. The molecular basis of HLAdisease association. Adv Hum Genet 1989; 18: 1-41.

25 David-Watine B, Israel A, Kourilsky P. The regulation and expression of MHC class I genes. Immunol Today 1990; 11: 286-92.

26 Foulis AK. The pathogenesis of beta cell destruction in type 1 (insulin-dependent) diabetes mellitus. $\mathcal{F}$ Pathol 1987; 152: 141-8.

27 Askonas BA, Openshaw PJM. MHC and antigen presentation. Immunol Today 1989; 10: 114-6.

28 Dani R, Artunes LJ, Ribeiro JEF, Nogueira CED, Ribeiro T. Immunological participation in chronic calcifying pancreatitis. Digestion 1974; 11: 333-7.

29 Nerenberg ST, Prasad R, Pedersen LD, Biskup NS. Radioimmunoassay for detecton of latent chronic ethanolic pancreatitis, an unrecognised clinical syndrome. Clin Chem 1980; 26: 214-8.

30 Monaco JJ, Cho S, Attaya M. Transport protein genes in the murine MHC: possible implications for antigen processing. Science 1990; 250: 1723-5.

31 Ballardini G, Mirakian R, Bianchi FB, Pisi E, Doniach D, Bottazzo GF. Aberrant expression of HLA-DR antigens on bile duct epithelium in primary biliary cirrhosis: relevance to pathogenesis. Lancet 1984; ii: 1009-13.

32 Norohna M, Bardolo O, Dreiling DA. Ethanol and the pancreas II. Pancreatic morphology of advanced ethanolic pancreatitis. Am f Gastroenterol 1981; 76: 120-4.

33 Kakizaki G, Sasahara M, Aikawa T, Matsuo M, Suguwara Y, Nakamura K, et al. On the pathogenesis of chronic ethanolic pancreatitis from the viewpoint of experimental results in pats. Int f Pancreatol 1987; 2: 101-6.

34 Suda K, Masatoshi M, Oyama T, Matsumoto Y. Histopathologic and immunohistochemical studies on ethanolic panchreatitis and chronic obstructive pancreatitis: special emphasis on ductal obstruction and genesis of pancreatitis. Am $\mathcal{F}$ Gastroenterol 1990; 85: 271-6.

35 Pederson NT, Anderson BN, Pederson G, Worning H. Chronic pancreatitis in Copenhagen. Scand $\mathcal{f}$ Gastroenterol 1982; 17: 925-31.

36 Basham TY, Merigant C. Recombinant interferon-gamma increases HLA-DR synthesis and expression. 7 Immunol 1983; 130: $1492-4$

37 Rosa F, Fellous $M$. The effect of gamma-interferon on MHC antigens. Immunol Today 1984; 5: 261-2.

38 Wan Y, Orrison B, Leiberman R, Lazarovici P, Ozato K. Induction of major histocompatibility class I antigens by induction of major histocompatibility class I antigens by 130: $276-3$.

39 Spencer J, Pugh S, Isaacson PG. HLA-D region antigen expression on stomach epithelium in absence of autoantibodies. Lancet 1986; ii: 983.

40 Khoury EL, Greenspan JS, Greenspan FS. Adrenocortical cells of the zona reticularis normally express HLA-DR antigenic determinants. Am $\mathcal{F}$ Pathol 1987; 127: 580-91. 